\title{
Age-related changes of microbiota in midlife associated with reduced saccharolytic potential: an in vitro study
}

\author{
Junkui Chen ${ }^{1}$, Xionge Pi', Wei Liu', Qunfang Ding ${ }^{2}$, Xin Wang ${ }^{1}$, Weiguo Jia ${ }^{2^{*}}$ and Liying Zhu ${ }^{1^{*}}$ (D)
}

\begin{abstract}
Background: Gut microbiota is critical in maintaining human health, of which diversity and abundance are subject to significantly reduce in seniors. Gut microbiota is reported to be stable across the long adulthood in general, but lack of careful examination, especially for the midlife people.

Results: To characterize the gut microbiota in midlife, we investigated the faecal microbiota between two groups of healthy people, young, 20-39years old, $n=15$; and midlife, 40-60 years old, $n=15$. Metabolic responses of the microbiota were studied through in vitro batch fermentation model. Although no difference was observed in the diversity indices between the two age groups, a wide range taxonomic changes were found in the faecal microbiota. Furthermore, substantial Bifidobacterium reduction was also found in both faecal and fermented samples. The faecal SCFAs are similar in both groups, as well as starch fermentation broth. However, after inulin fermentation, the acetate concentration and inulin degradation rate decreased while the gas production increased in midlife group, suggesting a deficiency of saccharolytic potential in midlife, especially for non-digestible carbohydrate.
\end{abstract}

Conclusions: Our data demonstrate that gut microbiota begins to change as early as in midlife. The reduction in Bifidobacterium dominates the change of the microbiota composition in midlife resulting in attenuated saccharolytic capacity of inulin, possibly leading to insufficient acetate production which might be associated with healthy problems in this transition period from young to elderly.

Keywords: Midlife, Microbiota, In vitro fermentation, SCFAs, Acetate, Gas production

\section{Background}

As human life expectancy increases, aging has become a public health issue. Numerous studies demonstrate that gut microbiota plays key roles in aging process [1-4]. Compared with young adults, the gut microbiota of elderly lacks diversity and is less stable combined with

\footnotetext{
*Correspondence: jiaweiguo@wchscu.cn; zhuliying@hotmail.co.jp

${ }^{2}$ The Center of Gerontology and Geriatrics, National Clinical Research Center of Geriatrics, West China Hospital, Sichuan University, Chengdu, P. R. China 'State Key Laboratory for Managing Biotic and Chemical Threats to the Quality and Safety of Agro-products, Institute of Plant Protection and Microbiology, Zhejiang Academy of Agricultural Sciences, Hangzhou, P. R. China
}

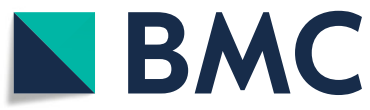

(C) The Author(s). 2021 Open Access This article is licensed under a Creative Commons Attribution 4.0 International License, which permits use, sharing, adaptation, distribution and reproduction in any medium or format, as long as you give appropriate credit to the original author(s) and the source, provide a link to the Creative Commons licence, and indicate if changes were made. The images or other third party material in this article are included in the article's Creative Commons licence, unless indicated otherwise in a credit line to the material. If material is not included in the article's Creative Commons licence and your intended use is not permitted by statutory regulation or exceeds the permitted use, you will need to obtain permission directly from the copyright holder. To view a copy of this licence, visit http://creativecommons.org/licenses/by/4.0/. The Creative Commons Public Domain Dedication waiver (http://creativecommons.org/publicdomain/zero/1.0/) applies to the data made available in this article, unless otherwise stated in a credit line to the data.

increased abundance of Bacteroidetes, Proteobacteria, particularly Gammaproteobacteria, and decreased abundance of Firmicutes and bifidobacteria [3]. The agingrelated dysbiosis of gut microbiota not only causes intestinal disorders but also extra-intestinal diseases, such as reduction of innate immunity, sarcopenia, and cognitive decline [5].

Midlife is a transition between young adulthood and elderly, when many physiological and psychological changes occur [6], leading to high morbidity rate, such as obesity [7] and type 2 diabetes (T2D) [8]. Furthermore, overweight/obesity and the vascular risk factors in midlife are demonstrated to associate with the later 
development of dementia $[9,10]$. One interesting question is whether gut microbiota starts to change in healthy midlife people. Previous mice study of three age groups has shown that polysaccharide utilization is higher in middle-aged mice than older mice [11]. An integrative study of aging mice demonstrated that the relative abundance of Akkermansia spp., Bifidobacterium spp. and Lactobacillus spp. decreases at middle age compared to young subjects [12]. Recently, Boehme and colleagues revealed a strong basal and stress-induced neuro inflammatory profile in middle-aged mice, which is associated with the changes in both microbiota compositions and their metabolites [6]. Interestingly, transfer of gut microbiota from young to middle-aged subjects extended the lifespan of the short-lived killifish [13]. Studies of microbiota in midlife human are highly limited. A recent cohort study of middle age (50-59 years old) to elderly individuals ( $>60$ years old) revealed that the presence of Bacteroidetes is positively associated with $\mathrm{CD} 8^{+}$ and negatively with $\mathrm{CD} 4^{+} / \mathrm{CD}^{+}$ratio, indicating tendency to immune diseases such as chronic infection, cancer or HIV [14].

Short chain fatty acids (SCFAs) are the primary metabolites produced by bacterial fermentation of nondigestible carbohydrates in the gastrointestinal tract. SCFAs act as important molecular signals between the microbiota and host [15], and regulate glucose homeostasis, appetite, energy intake, neuronal activity, immune system and inflammatory response [16]. In metabolic diseases, such as obesity, T2D [17, 18], cardiovascular diseases [19], as well as psychological dysfunction including cognitive process [20], SCFAs are regarded to play central roles. Based on the metagenomic studies, the gut microbiota of elderly is characterized by loss of genes involved in the SCFAs synthesis and decrease in the saccharolytic potential [21]. Six individual SCFAs, especially acetate, were reported to decrease in elderly compared to young subjects in a study of Parkinson's disease [22]. But SCFAs profile in midlife human is unknown. However, studies have shown SCFAs profile in caecum of middle-aged mice is different compared to young or older subjects. In aging mice model, acetate is found significantly increased in middle-aged mice compared to the older subjects $[6,12]$, butyrate and valerate levels are all higher than that in young mice [6].

Prebiotics are nutrient substances beneficial to the host system through selectively digestion by gut beneficial bacteria. Inulin is one of the well-accepted prebiotics and has shown to increase the abundance of Bifidobacterium, resist pathogen colonization and modulate the host immune systems in in vitro gut model systems and humans [23]. The human intervention trials for elderly have shown significant increasing of faecal bifidobacteria after digestion of inulin [24] and fructo-oligosaccharides [25], as well as higher molar ratio of acetate to butyrate and increased cholesterol excretion [24]. In middle-aged mice, feeding inulin supplementation reduces monocyte infiltration into brain and ameliorates agerelated microglia activation [6].

Metabolic profiles of gut microbiota can be investigated through in vitro batch fermentation [26], which allows large numbers of substrates and/or faecal samples to be tested quickly [27]. This method has been used in the study of inulin effect [28], healthy modulation by inulin [29] and galacto-oligosaccharide [30, 31]. Our previous studies also showed the in vitro batch fermentation of human feces helps reveal the fermentation characteristics of isomalto-oligosaccharides in colon [32].

Here, we used the batch fermentation model to compare the metabolic responses of faecal microbiota to inulin and soluble starch in midlife and young subjects. Combined with the analysis of microbiota composition, we found the age-related metabolic alterations were associated with the reduction of Bifidobacterium in midlife. We refer midlife as the people between 40 to 60 years old $[33,34]$.

\section{Results}

We investigated the microbial and metabolic features of the faecal microbiota in both young and midlife subjects using in vitro batch fermentation model. Soluble starch, a representative of digestible carbohydrate, and inulin, a representative of non-digestible carbohydrate, were selected to study the metabolic responses. Both the feces and fermented broth samples were processed and subjected to $16 \mathrm{~S}$ rRNA gene sequencing and SCFAs detection. We also determined gas production in the fermentation model as it is one of the most production metabolites beside SCFAs.

\section{Difference in the structure of the microbiota community}

Based on the results of the16S rRNA gene sequencing, the alpha-diversity indices, such as Shannon, Simpson and Chao1 index are similar between midlife and young in both faecal and fermented samples (Fig. 1a). We also assessed overall community compositions by drawing bar charts of relative abundance at different taxonomic levels, of which at genus level was shown in supplementary (Supplemental Fig. 1). With the comparison of the relative abundance among top ten genera, Bifidobacterium in young group were significantly higher than those in midlife subjects (Fig. 1c). Furthermore, beta-diversity analysis was performed by calculating Bray-Curtis distance matrix to reveal differences between young and midlife group, of which the significance was examined by ANOSIM. Unfortunately, no significant difference was found between 


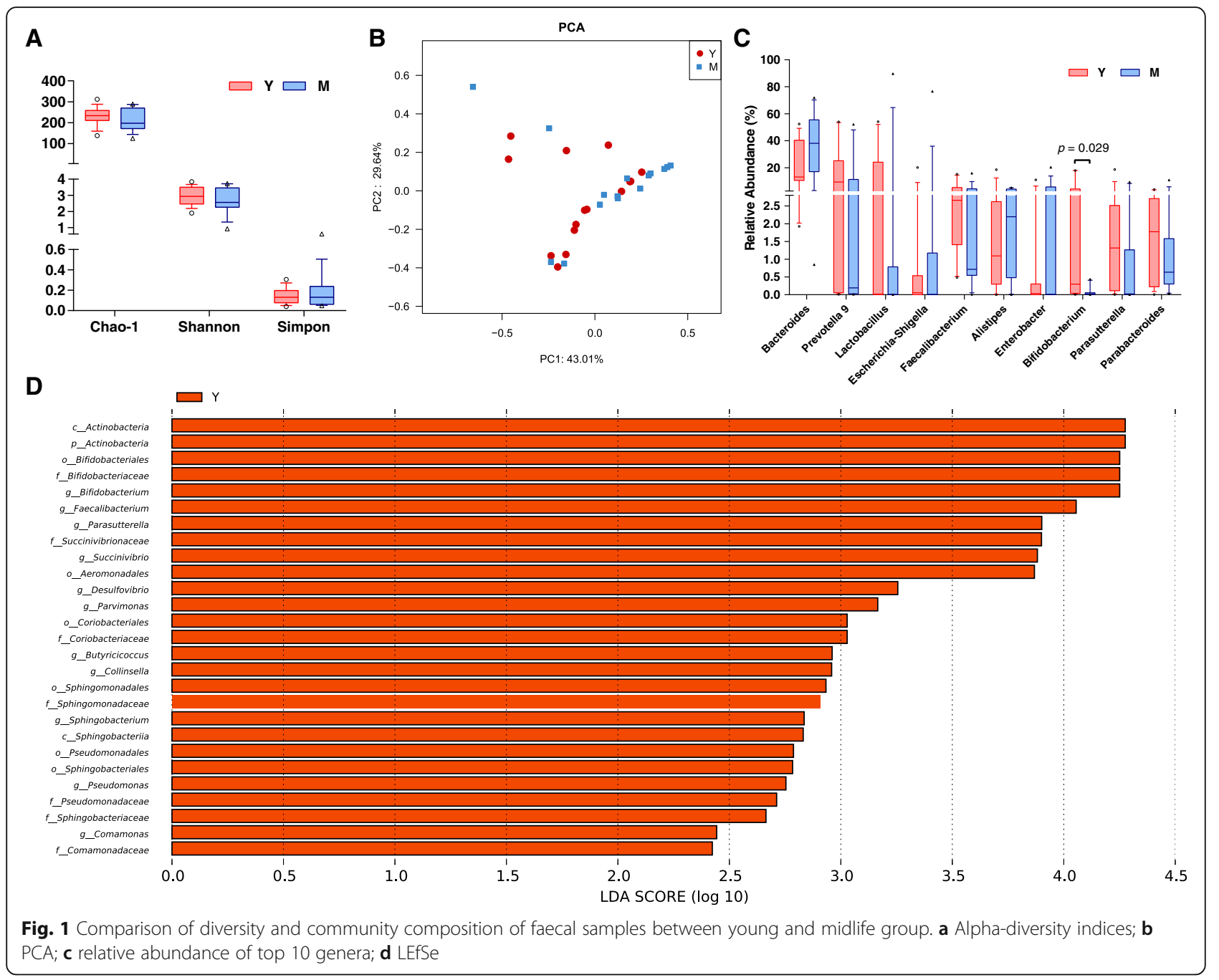

the two age groups (Supplemental Fig. 2). Similarly, PCA did not divided the faecal samples into two groups (Fig. 1b). Interestingly, the PCA scattered plots of the inulin broth samples can be obviously clustered on age (Fig. 2b) despite of no difference between age groups in the starch broths (Fig. 2a).

\section{Impact of environmental factors on microbiota}

Canonical Correspondence Analysis (CCA) was performed to investigate the effects of age and carbon source on the variation in microbiota (Fig. 3). The scatter plot displayed the clustering on age and culture medium. The small percentage of the axis suggests that although age and carbon are not the only sources causing the variation in the system, they are the major ones with more contribution from carbon source than age. This is further supported by the observation that clustering plot shifts in the direction of both medium and age.

\section{Difference in taxonomic composition Faecal samples}

Linear discriminant analysis (LDA) effect size (LEfSe) was used to identify the age-related bacterial feature in the microbiota before (Fig. 1d) and after fermentation (Fig. 4). As for the faecal samples, LEfSe revealed 27 taxa overrepresent in young group but none in midlife group (Fig. 1d). The taxa involve 11 genera in 4 phyla, suggesting a wide range of changes in relative abundance between youth and midlife. Among the 27 taxa, the top 5 taxa were taxa within phylum Actinobacteria, including Actinobacteria (class), Actinobacteria (phylum), Bifidobacteriales (order), Bifidobacteriaceae (family) and Bifidobacterium (genus) in turn. Bifidobacteria dominates the infant gut microbiota and reduces with age [35]. Similar to the observation that Bifidobacterium disappears in middle-aged mice [12], our data reveal that Bifidobacterium is the genus declined most in human midlife. Furthermore, 


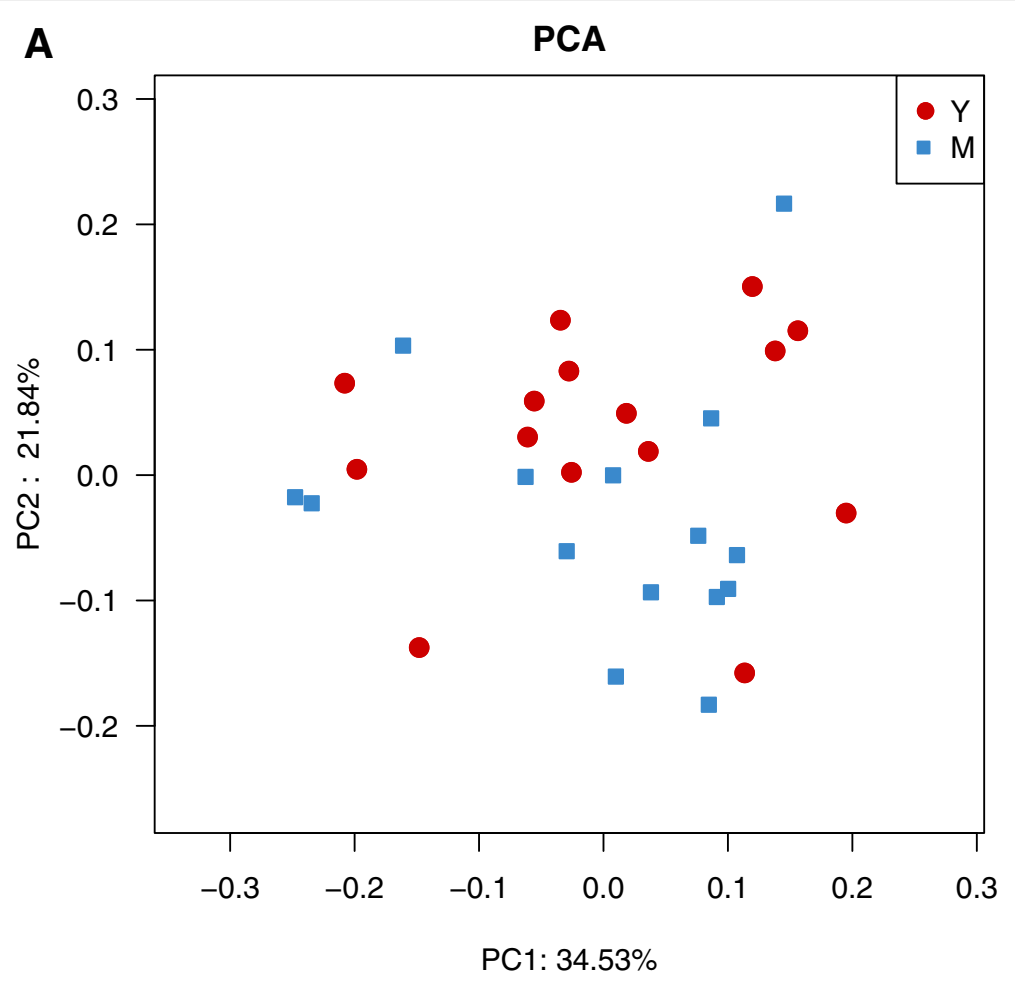

B

PCA

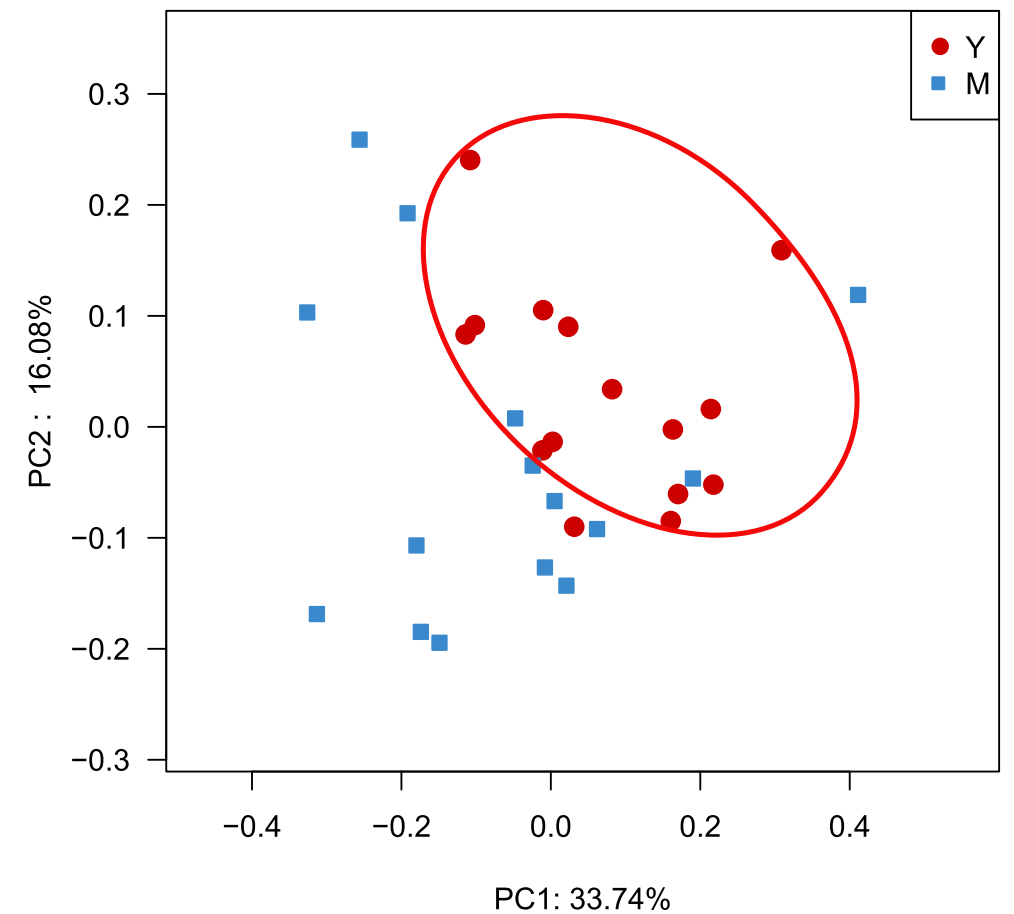

Fig. 2 Comparison of the microbial community structures for fermented broth samples between the two age groups. PCA of the microbiota of the broth samples after soluble starch fermentation (a), and inulin fermentation (b) 


\section{CCA}

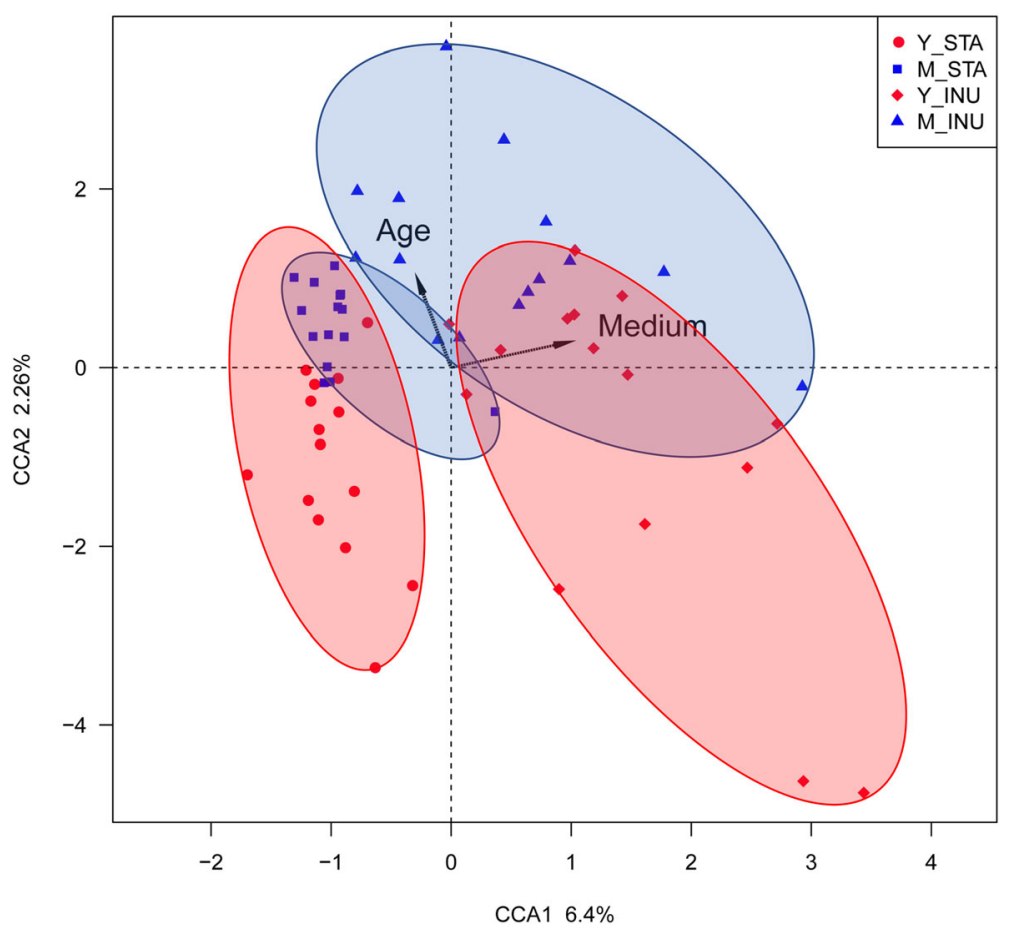

Fig. 3 The impact of age and culture medium on microbiota. CCA was used to show the variation in microbiota composition affected by the age groups and the sole carbon hydrates. The samples from midlife (blue) and young (red) group were plotted. The starch fermentation samples were clustered by solid line and inulin fermented samples were clustered by dotted line

8 taxa, including Collinsella and Coriobacteriales (order) and Coriobacteriaceae (family), were observed to decline in midlife. This is also similar to the observation in mice that the relative abundance of both Bifidobacterium spp. and Coriobacteriaceae spp. decreases strongly and significantly in middle-aged mice compared to young subjects [12]. Additionally, four genera, including Faecalibacterium, Butyricicoccus, Desulfovibrio and Parasutterella were abundant in young group but absent in midlife group. Faecalibacterium and Butyricicoccus are the main butyrate products found in the intestine [36, 37]. Thus, the relative abundance of butyrate-producing bacteria differs between young and midlife groups. Desulfovibrio is the dominant sulfate-reducing bacteria in the colon and reduces sulfate compounds to hydrogen sulfide $\left(\mathrm{H}_{2} \mathrm{~S}\right)$ [38], which is one of the main microbiotaderived gases contributing to human colonic homeostasis [39]. Parasutterella was the one changed most in phylum Proteobacteria, a result also observed in aging mice [12]. Parasutterella is a core component of human gut microbiota and produces various metabolites including aromatic amino acid, bilirubin, purine, and bile acid derivatives [40]. Our results thus suggest the core composition in gut microbiota begins to reduce in midlife.

\section{Starch fermented samples}

After starch fermentation (Fig. 4a), there were 11 taxa overrepresented in young group, predominated by Selenomonadales (order), Negativicutes (class), Veillonellaceae (family), Desulfovibrio (genus), Bifidobacterium (genus) and its belonging family and order, Comamonas (genus) and its belonging family, Catenibacterium (genus) and Bacillales (order). In contrast, only 6 taxa were overrepresented in midlife, including Proteobacteria (phylum), Peptoniphilus (genus), Lachnospiracea-incertae_sedis (genus) and Staphylococcus (genus). Veillonellaceae, belonging to class Negativicutes and further belonging to order Selenomonadales, is reported to play roles in host carbohydrates metabolism [41]. Veillonellaceae and its higher order taxa are the top taxa in starch fermentation indicates their roles seem to be more important for starch degradation compared to Bifidobacterium.

\section{Inulin fermented samples}

In term of the inulin fermentation (Fig. 4b), LEfSe revealed 8 taxa overrepresented in young group compared to midlife group. Five are taxa within phylum Actinobacteria, including Bifidobacterium and the remaining 3 taxa are Catenibacterium 

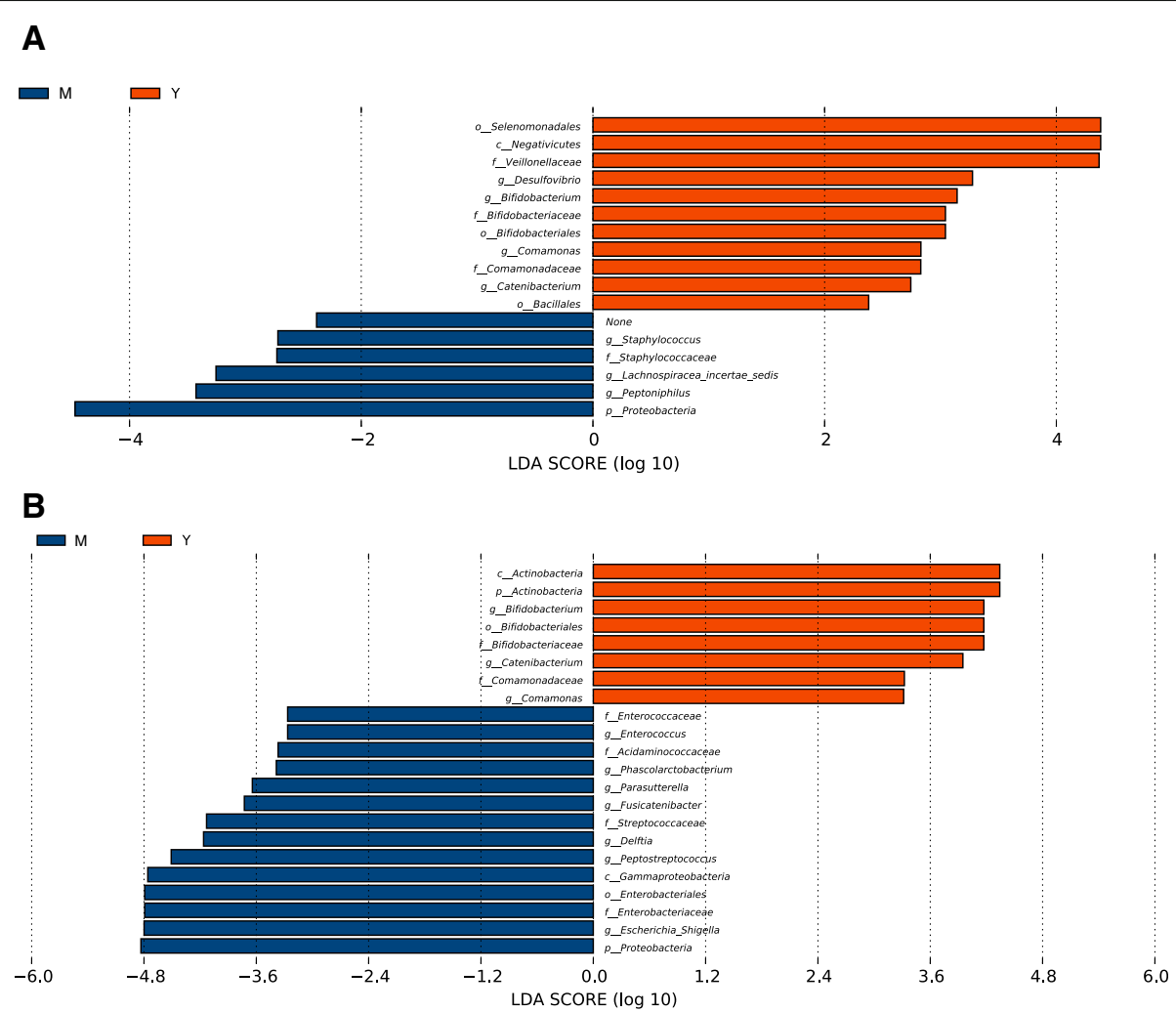

Fig. 4 The microbial feature of the microbiota after fermentation. LEfSe of microbiota of the broth samples after soluble starch fermentation (a) and inulin fermentation $(\mathbf{b})$ were performed. The feature taxa in midlife $(M)$ and young $(Y)$ group were shown according to LDA scores

(genus), Comamonas (genus) and its belonging family. These taxa are all present in LEfSe results of both feces and starch broth, suggesting they are the key bacteria in young microbiota for saccharolytic process. On the other side, LEfSe identified 14 taxa overrepresented after inulin fermentation in midlife group. The top 5 taxa are Proteobacteria (phylum), Escherichia-Shigella (genus), Enterobacteriaceae (family), Enterobacteriales (order), Gama-proteobacteria (class), and the remaining taxa are Peptostreptococcus (genus), Delftia (genus), Streptococcaceae (family), Fusicatenibacter (genus), Parasutterella (genus), Phascolarctobacterium (genus), Acidaminococcareae (family), Enterococcus (genus), Enterococcaceae (family). The shared taxa number within young group after fermentation is 8 , contrast to it however, only 1 taxon, Proteobacteria (phylum) is common in midlife group, suggesting that the reduction of bifidobacteria and increase of Proteobacteria can be taxonomic characteristics for midlife microbiota to ferment carbohydrates.

\section{Detection of Bifidobacterium amount}

To confirm the LEfSe results regarding Bifidobacterium, qPCR was performed for the faecal samples (Fig. 5a) and the fermented samples (Fig. 6a). The abundances of Bifidobacterium in midlife group were overall lower than that in young group, particularly in the faecal samples $(p=0.031)$ (Fig. 5a).

\section{Difference in metabolic response}

SCFAs in both feces and fermented broths were measured. As shown in Fig. 5c, most individual SCFAs in the feces in midlife group were lower than those in young group, except for propionate, but without significant difference. After starch fermentation, the most individual SCFAs in midlife were lower than those in young group (Fig. 6c-h), which is similar to the case in feces. However, after inulin fermentation, the reduction of acetate in midlife (Fig. 6c) was significant $(p=0.0002)$ compared to young group despite of similar level of butyrate and propionate in the two age groups. A similar result has been observed in aging mice that butyrate and propionate do not differ between two age groups, but acetate is significantly lower in old mice [12]. It is worth pointing out that the total SCFAs in midlife broth of inulin declines pronouncedly $(p=0.052)$. In addition, inulin fermentation also caused significant gas production increase in midlife group $(p=0.008)$ (Fig. 6i), and inulin degradation decrease $(p=0.002)$ compared to 

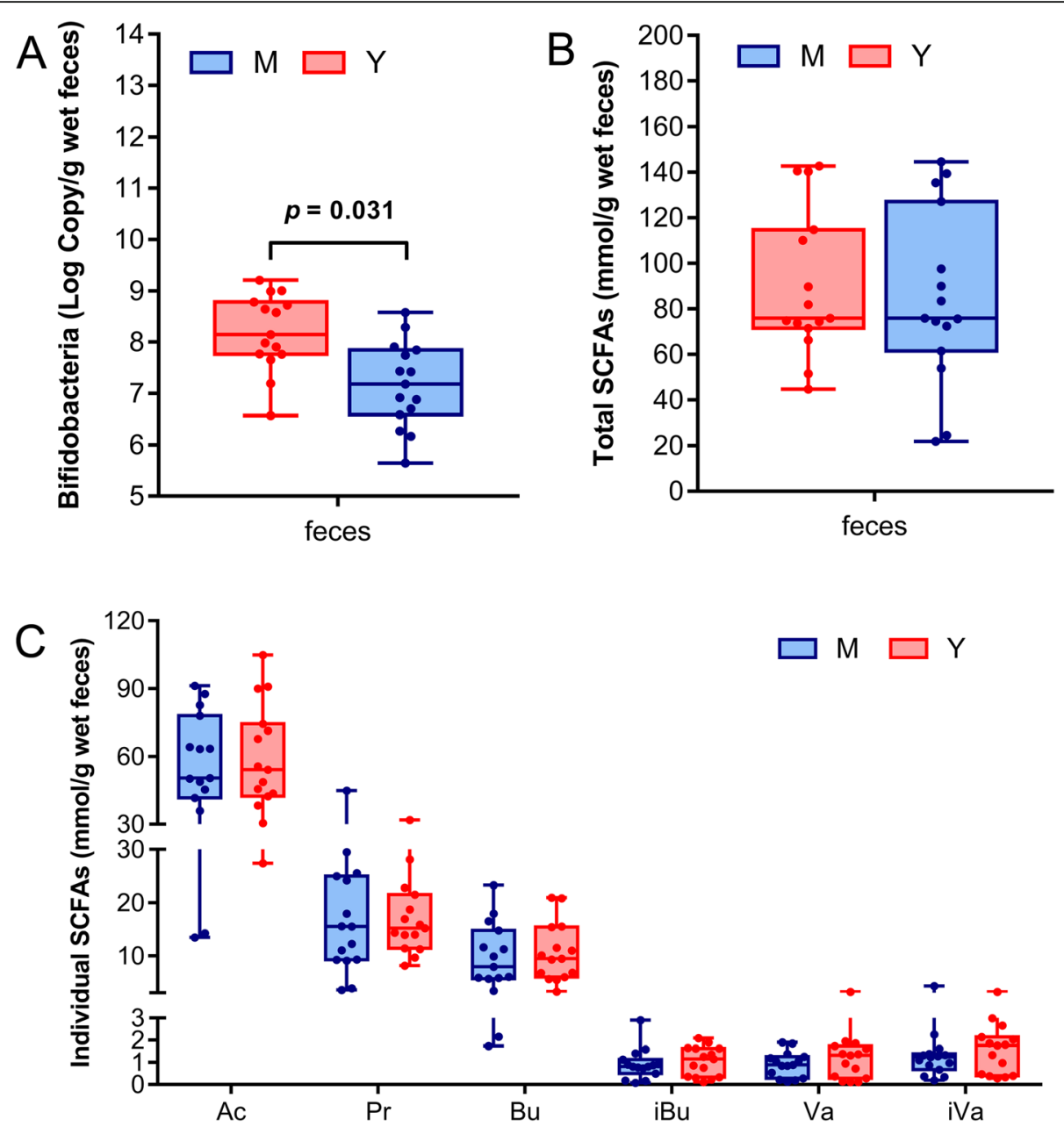

Fig. 5 Comparison of the Bifidobacterium number and SCFAs in faecal samples. The faecal Bifidobacterium numbers of midlife (M) and young (Y) groups were determined by qPCR (a). The faecal SCFAs were determined by GC. The total SCFAs (b) was the sum of 6 individual acids (c). Ac: acetate, Pr: propionate, Bu: butyrate, iBu: isobutyrate, Va: valerate, iVa: isovalerate

young group (Fig. 6j), a result comparable to the decline of saccharolytic capability in aging mice [11].

\section{Correlation between the metabolites and the genera}

To understand the contribution of genera to the altered metabolites, Spearman's correlation coefficient was used to analyze the association between metabolites concentration and genus abundance. As for the starch fermentation, 3 genera, including Bifidobacterium, Desulfovibrio and Staphylococcus, showed correlation with six metabolic parameters (Fig. 7a). As for inulin fermentation, 8 genera included Fusicatenibacter, Phascolarctobacterium, Peptostreptococcus, Delftia, Bifidobacterium, Parasutterella, Comamonas and Catenibacterium were involved and correlated with seven metabolic parameters (Fig. 7b).

As shown in Fig. 7b, only two genera, Bifidobacterium and Parasutterella, showed significant correlation with acetate production, which were both positive. Upon the heatmap, Bifidobacterium had stronger correlation with acetate production than Parasutterella, suggesting the reduced acetate in midlife group might be responsible for the less abundance of Bifidobacterium, a powerful acetate producer. On the other hand, Peptostreptococcus and Bifidobacterium were the only genera shown significant correlation with gas production, which was positive and negative, respectively. This indicated the increased gas production in midlife group also seemed to be due to the absence of Bifidobacterium, an inhibitor of gas production.

\section{Discussion}

We studied the difference of faecal microbiota between midlife and young subjects by the investigation of both the community structures and the metabolic responses before and after in vitro fermentation. Our results suggested multi-aspect changes in midlife microbiota and its functions. 

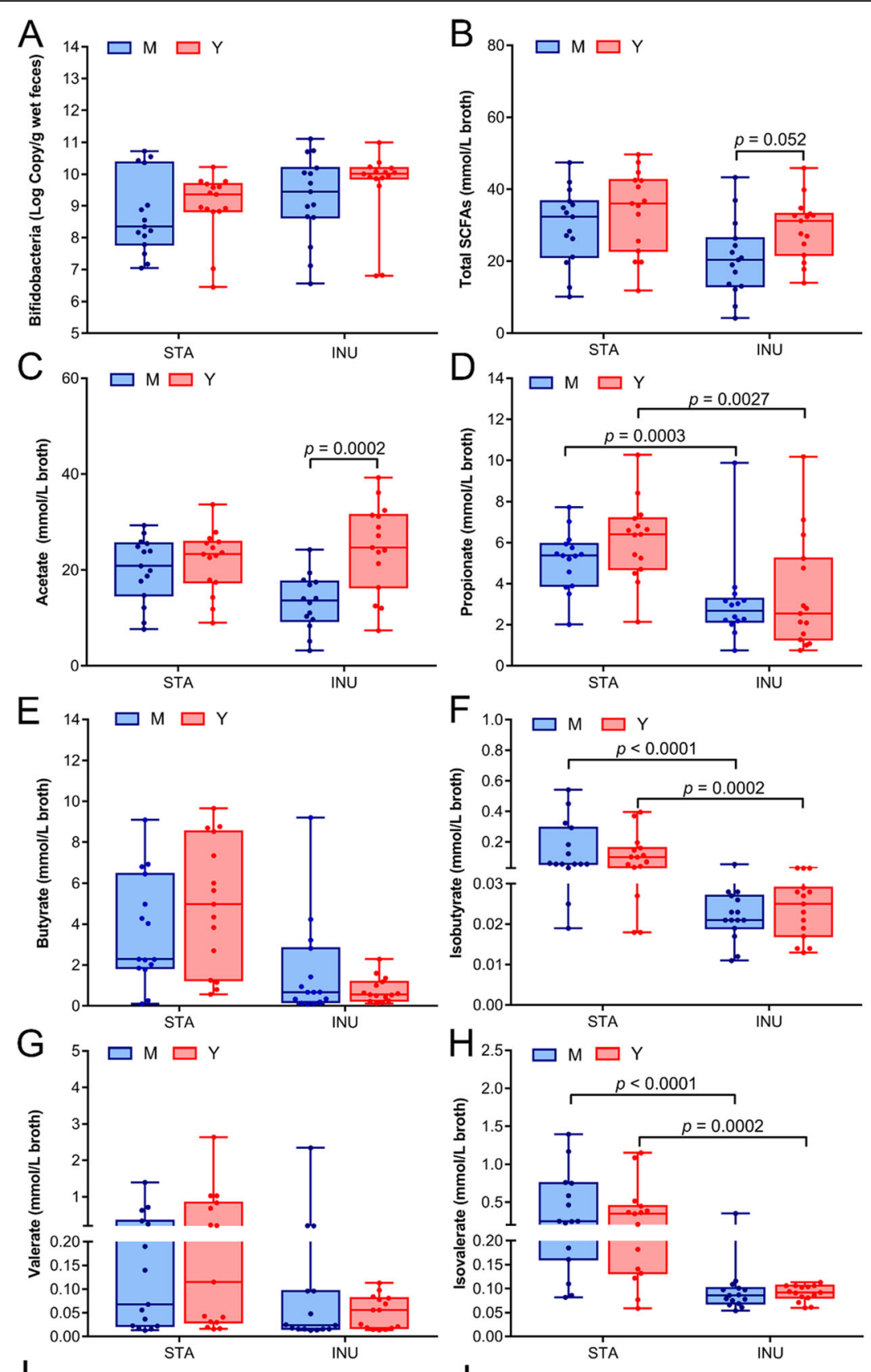

$\mathrm{H}_{2.5} \square \mathrm{M} \square \mathrm{Y}$
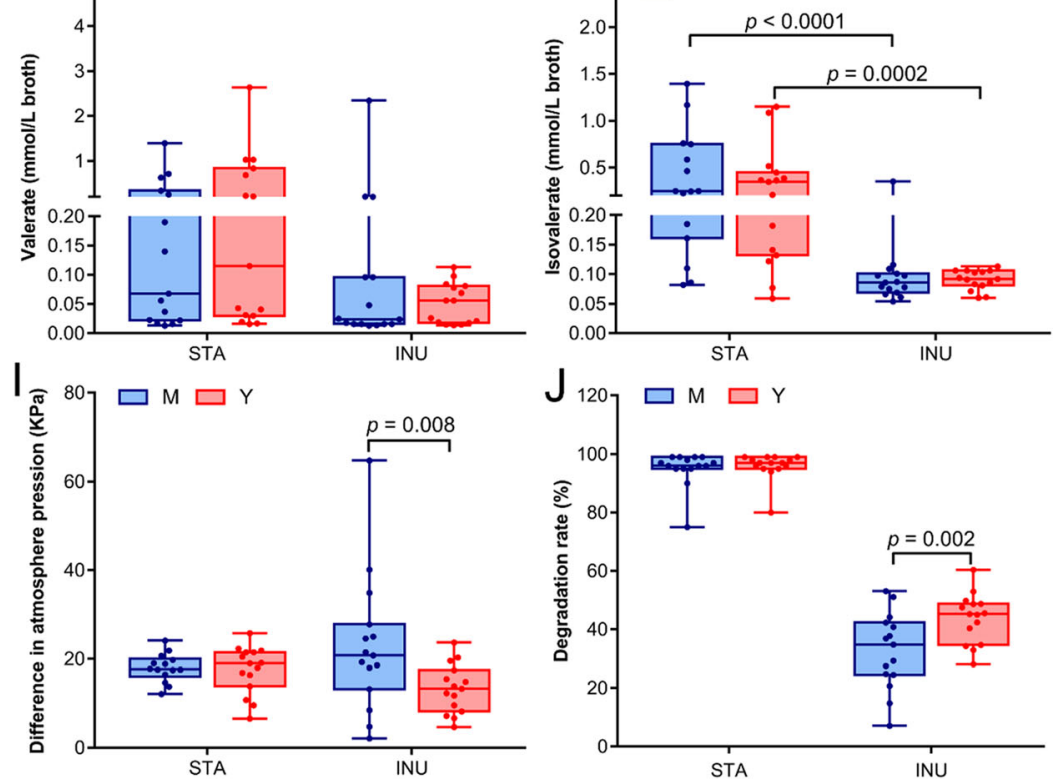

Fig. 6 (See legend on next page.) 
(See figure on previous page.)

Fig. 6 Comparison of the Bifidobacterium number and metabolic responses after in vitro batch fermentation. The faecal slurries of midlife (M) and young $(Y)$ groups were subjected to in vitro fermentation of starch (STA) and inulin (INU). The Bifidobacterium numbers are determined by qPCR (a). The metabolic responses including SCFAs (b-h), gas productions (i) and degradation rate of the sole carbohydrate (j) were determined. The SCFAs were determined by GC. The total SCFAs (b) is the sum of 6 individual acids including acetate (c), propionate (d), butyrate (e), isobutyrate $(\mathbf{f})$, valerate $(\mathbf{g})$ and isovalerate $(\mathbf{h})$. The gas production after fermentation was measured by the air pressure difference of the vial (i). The degradations of starch and inulin after fermentation were detected by TLC (j)

We observed a significant reduction of Bifidobacterium in both midlife faecal and fermented microbiota. The community composition analysis revealed that Bifidobacterium was significantly reduced in midlife faecal microbiota compared to young subjects, which was confirmed by qPCR. Furthermore, LEfSe showed that young group had more abundance Bifidobacterium than midlife group not only in feces but also in the fermented samples both of soluble starch and inulin. Bifidobacterium is thought to play pivotal roles in

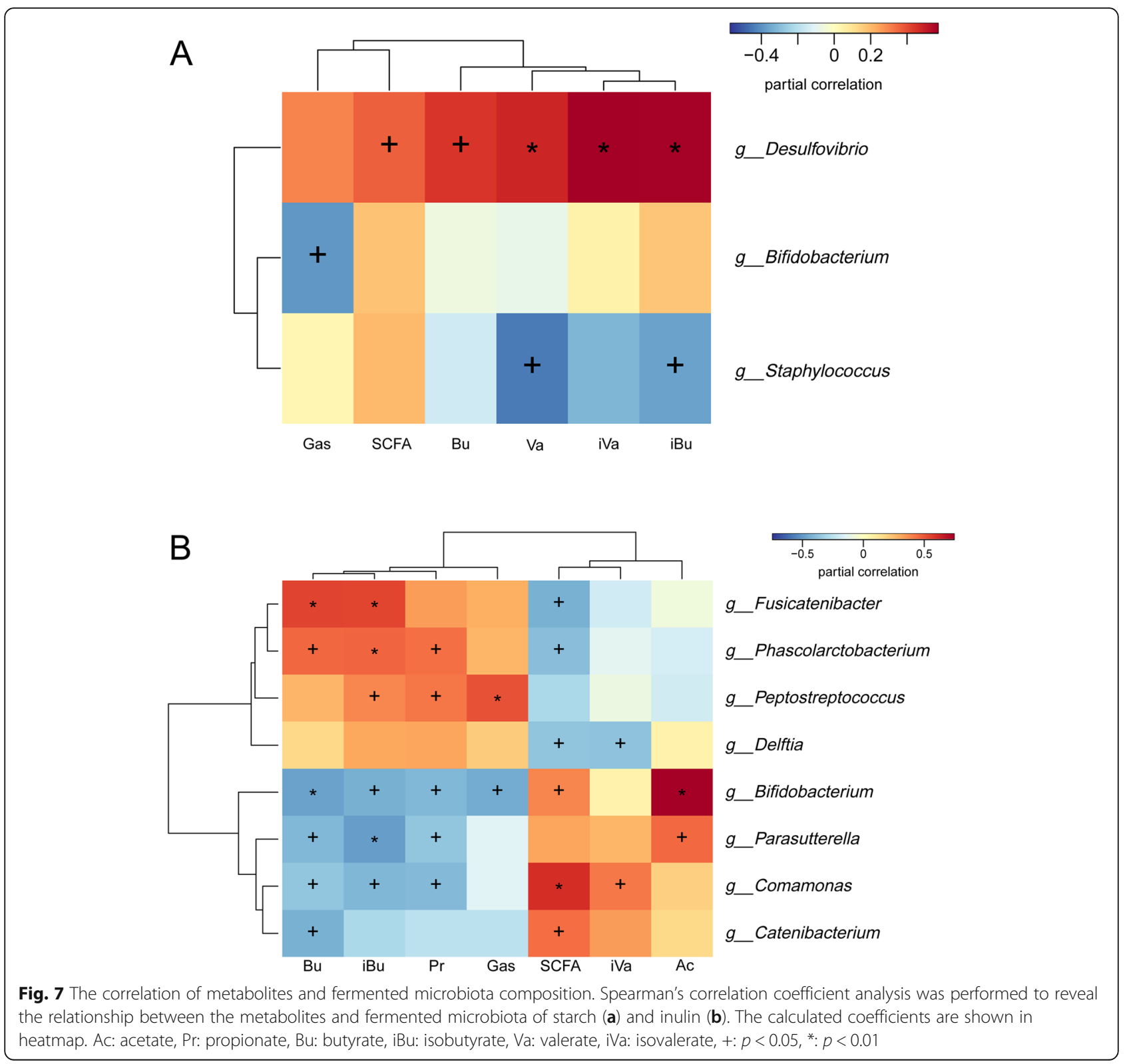


maintaining human health $[42,43]$, and its numbers decline is one of the most marked changes in the elderly gut [44]. Thus, the reduced Bifidobacterium seems to be the age-related feature in midlife microbiota. In addition, LEfSe also revealed that the core composition in gut microbiota begins to reduce in midlife feces, which involved 27 taxa, such as genus Faecalibacterium which also associates with the grip strength in elderly [45]. On the other hand, an age-related change in the microbial community structure of midlife was revealed by PCA after in vitro fermentation of inulin and the subsequent analysis of CCA, despite of similarity in the diversity analysis, including alpha-diversity indies and the distance matrix calculating-based beta-diversity analysis, which agrees with the previous reports that the faecal microbiota structures of 20 to 60 years old are in a stable stage in this aspect $[46,47]$. Hence, we conclude that microbial alterations associated with aging also occur in midlife, rather than the previous thought to begin in elderly. This is consistent with previous report of agerelated functional characteristics in metagenomes that midlife with age 38-43 differentiates from young and elderly and constitutes a good watershed in data clustering between age groups [48].

The metabolic responses to inulin were significantly different between midlife and young group. After inulin fermentation, midlife group had lower acetate and higher gas production compared to young group, as well as lower inulin degradation rate. Based on the Spearman's correlation coefficient analysis, Bifidobacterium was positively correlated with acetate production and negatively correlated with gas production. Thus, the absence of Bifidobacterium in midlife seemed to contribute to both the significantly increased gas production and the significantly reduced acetate after inulin fermentation. This is supported by the recent reports that Bifidobacterium is lack of hydrogenase genes in its genome [49] and acetate is its main metabolite [50]. In human intervention trial of resistant starch, some volunteers were found as "nonresponders" with $>60 \%$ of unfermented starch remaining in their stools while others with $<4 \%$ [51]. The difference in the initial composition of individual's gut microbiota may be the cause [52, 53]. Therefore, the reduction of Bifidobacterium in midlife feces seems to be responsible for the significant drop in metabolic responses to inulin for midlife microbiota.

Bifidobacteria is reported to own the capacity to ferment a variety of carbohydrate and fiber compounds [54]. The saccharolytic genes were found to decrease in elderly gut microbiota [21] and older age mice [11]. However, the attenuated saccharolytic capacity only found in the fermentation of inulin but not starch, suggesting that the microbial changes in midlife associated with aging are still in initial stage, leading to a partial functional decline.

In this study, acetate was significantly reduced in midlife after inulin fermentation compared to young group. SCFAs have a number of potential roles in modulating metabolic health [19]. Acetate is most productive acid among SCFAs and appears to stimulate leptin secretion in adipocytes, involving energy balance and appetite [16], conditioning immune cell in response to protect against T2D [55] and regulating blood pressure [56, 57]. And the impaired acetate production might be associated with weight gain in midlife [58]. Considering that approximately $44 \%$ acetate in plasma is microbiotaderived [59], the reduced production of acetate by microbiota might be associated with the physiological changes in midlife which leading obesity [7], T2D [8] and cardiovascular disease [10].

Interestingly, contrast to significantly reduced inulin degradation and acetate production, the reduction in number of Bifidobacterium is not significant after inulin fermentation. Concerning its diversity of inulin catabolism [60] and its niche- and strain-specific acetate production [61], the loss of certain Bifidobacterium species or strains that produce large amounts of acetate might be the reason. This is supported by a recent study that changes in the composition of Bifidobacterium species occur with ageing [35]. Addition to the roles of acetate in the healthy problem of midlife, such as obesity and T2D, it is reported that bifidobacteria-produced acetate improves intestinal defense mediated by epithelial cells and thereby protects the host against lethal infections [62]. Therefore, further study is needed to clarify the species of Bifidobacterium reduced in midlife.

\section{Conclusions}

The gut microbiota compositions and the metabolic responses of the microbiota for midlife and young subjects were investigated by using in vitro batch fermentation of starch and inulin. Bifidobacterium reduction is identified as the feature of midlife microbiota and results in deficient saccharolytic capacity leading to a significant decline of acetate production in inulin fermentation, which seems to associate with the diseases prevalent in midlife. Overall, our results indicate the advantage of in vitro batch fermentation model in both microbiota and its metabolites analysis.

\section{Methods}

\section{Subjects}

Healthy volunteers aged $20-39$ and $40-60$ years old were recruited, 15 individuals in each group. The average age of the youth group (20-39 years old) was 
$26.6 \pm 1.6$ years old and of the mid-life group (40-60 years old) was $50.9 \pm 1.6$ years old. Exclusion criteria included: 1) Any gastrointestinal disease such as IBS and IBD; 2) Presence of severe diabetes and unstable thyroid disease; 3) Pregnant or lactating women; 4) Taking probiotics, prebiotics and antibiotics agents within 4 weeks prior to the faecal samples collection. All volunteers were provided with informed, written consent and instructed to collect the feces.

\section{Fermentation media}

Batch fermentation was conducted as described previously [63]. In brief, basic growth medium (YCFA) contained the following $(\mathrm{g} / \mathrm{L})$ : tryptone 10 ; yeast extract 2.5 ; L-cysteine 1; $\mathrm{NaCl} 0.9 ; \mathrm{CaCl}_{2} \cdot 6 \mathrm{H}_{2} \mathrm{O} 0.09 ; \mathrm{KH}_{2} \mathrm{PO}_{4} 0.45$; $\mathrm{K}_{2} \mathrm{HPO}_{4}$ 0.45; $\mathrm{MgSO}_{4} \cdot 7 \mathrm{H} 2 \mathrm{O}$ 0.09; vitamin I 200; hemin solution $2 \mathrm{ml}$. Vitamin I solution contained the following compositions $(\mathrm{mg} / \mathrm{ml})$ : vitamin B8 0.05; vitamin B12 0.05 ; acid 4-aminobenzoïque 0.15 ; vitamin $\mathrm{B} 90.25$; pyridoxamine 0.75 . The hemin concentration is $1 \mathrm{mg} / \mathrm{ml}$ in $1 \mathrm{M}$ sodium hydroxide. Inulin (Fengning Ping An HighTech, China, VILOF ${ }^{-}$NanoIN) or soluble starch (SigmaAldrich, V900508) was added (8g/L) as the sole carbon source. After added resazurin $(0.1 \mathrm{mg} / \mathrm{L})$, the indicator of anaerobic condition, the medium was adjusted to $\mathrm{pH}$ 6.5 and dispensed $5 \mathrm{ml}$ into a $10 \mathrm{ml}$ bottle with flushing $\mathrm{N}_{2}$ before autoclave.

\section{Batch fermentation}

Fresh faecal samples $(0.8 \mathrm{~g})$ were homogenized with 8 $\mathrm{mL}$ of $0.1 \mathrm{M}$ anaerobic phosphate-buffered saline $(\mathrm{pH}$ 7.0) using an automatic faecal homogenizer (Halo Biotechnology Co. LTD., China) to make 10\% (w/v) slurries as soon as the faecal samples arrived the laboratory. And $0.5 \mathrm{ml}$ of the faecal slurry was inoculated to $5 \mathrm{ml}$ growth media and subjected to anaerobic fermentation at $37^{\circ} \mathrm{C}$.

After $24 \mathrm{~h}$ of fermentation, the air pressure difference of the serum bottle was measured. Subsequently, the broth was aliquoted and centrifuged. The supernatant and precipitation of the broth were stored at $-30^{\circ} \mathrm{C}$ for the further metabolic analysis and DNA extraction.

\section{Determination of gas production}

The gas production capacity was determined by the air pressure difference of the serum bottle using digital manometer (Dongguan Xintai Instrument Co., Ltd., China, HT1895).

\section{Thin-layer chromatography (TLC)}

Degradation of starch and inulin was detected by TLC analysis described in the previous study [32]. The densities of the oligosaccharide spots in the TLC images were quantified by Quantity One (Bio-Rad, U.S.). The consumed amounts of oligosaccharides by bacteria were calculated by the difference of the densities between the medium and the broth. The degradation rate of oligosaccharide was the percentage of the amount consumed versus its original amount in the medium.

\section{SCFAs determination}

SCFAs were determined via gas chromatography as described previously [64]. Briefly, $1 \mathrm{~mL}$ of broth or faecal slurry was acidified by $0.2 \mathrm{~mL}$ of $25 \%(\mathrm{w} / \mathrm{v})$ metaphosphoric acid and centrifuged at $14,000 \mathrm{~g}$ for $2 \mathrm{~min}$. The filtered supernatant was analyzed on GC-2010 Plus gas chromatograph (Shimadzu, Japan) equipped with an $\mathrm{H}_{2}$ flame ionization detector. A DB-FFAP column $(0.32$ $\mathrm{mm} \times 30 \mathrm{~m} \times 0.5 \mu \mathrm{m}$ ) (Agilent Technologies, US) was used to separate SCFAs. Crotonic acid (trans-2-butenoic acid) was used as an internal standard.

\section{DNA extraction}

Bacterial genomic DNA was extracted using QIAamp DNA Stool Mini Kit according to the manufacturer's instructions (Qiagen, Germany). The concentration of extracted DNA was determined by NanoDrop ND-2000 (NanoDrop Technologies, U.S.), and confirmed by $1.0 \%$ agar gel electrophoresis [65].

\section{$16 \mathrm{~S}$ rRNA gene sequencing}

Bacterial 16S rRNA genes of V3-V4 were amplified using barcoded primers 341F (5'-CCTAYGGG RBGCASCAG-3') and 806R (5'-GGACTACNNG GGTATCTAAT-3'). Amplicons were extracted from $2 \%$ agarose gels and purified using AxyPrep DNA Gel Extraction Kit (Axygen Biosciences, Union City, CA, U.S.) according to the manufacturer's instructions and quantified using QuantiFluor ${ }^{\mathrm{rm}}$-ST (Promega, U.S.). Purified amplicons were pooled in equimolar and paired-end sequenced $(2 \times 250)$ on Illumina MiSeq platform according to the standard protocols, performed by Lizhen Biopharmaceutical technology co., Ltd., Hangzhou, China.

Sequences were identified by barcodes using Quantitative Insights in Microbial Ecology (QIIME) 1.8.0 pipeline. Low quality sequences were removed for further analysis. Sequences were clustered into the operational taxonomic units (OTUs) with 97\% similarity cutoff. The OTUs were assigned to taxa using the Greengenes database 2 (Release 13.8). A phylogenetic tree of representative sequences was built. The within-community diversity (alpha-diversity) indies, such as Chao1, Simpson and Shannon, were calculated by the $\mathrm{R}$ "phyloseq" package. Beta-diversity was estimated by calculating Bray-Curtis distance matrix by $\mathrm{R}$ package vegan and ggplot2 and statistically examined by ANOSIM. PCA was performed to explore 
variance in microbiota composition. Age and carbohydrate source for the culture were treated as environmental factors. Their impact on microbiota was evaluated by CCA. Age dependent features were identified by using LEfSe. Heatmaps were built to show Spearman's correlation coefficient between metabolites and microbiota composition at genus level. The input consisted of the OTUs with relative abundance more than $0.1 \%$ at least in one sample. The raw reads were deposited into the NCBI Sequence Read Archive (SRA) database (Accession Number: SRP187258).

\section{Quantitative PCR (qPCR)}

The number of Bifidobacterium in the feces and broth samples were assessed by qPCR in CFX96 TM Real-time PCR Detection System (Bio-Rad, U.S.) with specific primers Bifi601F: 5'-GGGTGGTAATGCCGGATG and Bifi601R: 5'-TAAGCCATGGACTTTCACACC-3'. The qPCR was performed as described previously $[32,66]$.

\section{Statistical analysis}

Statistical analyses were performed using MannWhitney test or multiple $\mathrm{t}$ tests using Holm-Sidak method by GraphPad Prism 7.00 software. $p$-values < 0.05 were considered statistically significant.

\section{Supplementary Information}

The online version contains supplementary material available at https://doi. org/10.1186/s12866-021-02103-7.

Additional file 1: Supplemental Fig. 1. Relative abundance of genus taxonomic level within individual faecal samples.

Additional file 2: Supplemental Fig. 2. ANOSIM test of Bray-Curtis distance matrix calculation. (A) Faecal samples, (B) broth samples of starch fermentation, (C) broth samples of inulin fermentation.

\section{Abbreviations}

CCA: Canonical Correspondence Analysis; LEfSe: Linear discriminant analysis (LDA) effect size; PCA: Principal Component Analysis; qPCR: quantitative PCR; SCFAs: short chain fatty acids; T2D: type 2 diabetes; TLC: thin-layer chromatography

\section{Acknowledgements}

Not applicable.

\section{Authors' contributions}

XW, WJ and QD conceived the study and provided samples. JC, XP and WL carried out experimental work. JC and LZ analyzed data. JC and XW wrote first draft of the manuscript. LZ prepared the final version of the manuscript. All authors have read and approved the final manuscript.

\section{Funding}

This work was supported by Ministry of Science and Technology of the People's Republic of China (2017YFD0400300); National Natural Science Foundation of China (31870106); and Zhejiang Provincial Science and Technology Department (2018C02048). The funding bodies played no role in the study design, the data collection, analysis and interpretation of the data, or the manuscript writing.

\section{Availability of data and materials}

The 16S rRNA gene amplicon sequence dataset has been uploaded to the NCBI Sequence Read Archive (SRA) under accession number SRP187258 (https://www.ncbi.nlm.nih.gov/sra/?term=SRP187258). Other datasets analyzed during the current study are available from the corresponding author on reasonable request.

\section{Ethics approval and consent to participate}

The study was approved by the West China Hospital Ethics Committee (2018 No. 286). All volunteers were provided with informed, written consent and instructed to collect the feces.

Consent for publication

Not applicable.

\section{Competing interests}

The authors declare that they have no competing interests.

Received: 18 May 2020 Accepted: 2 February 2021

Published online: 15 February 2021

\section{References}

1. Vaiserman AM, Koliada AK, Marotta F. Gut microbiota: a player in aging and a target for anti-aging intervention. Ageing Res Rev. 2017;35:36-45. https:// doi.org/10.1016/j.arr.2017.01.001.

2. Salazar N, Valdes-Varela L, Gonzalez S, Gueimonde M, de Los Reyes-Gavilan CG. Nutrition and the gut microbiome in the elderly. Gut Microbes. 2017; 8(2):82-97. https://doi.org/10.1080/19490976.2016.1256525.

3. Maynard C, Weinkove D. The gut microbiota and ageing. Subcell Biochem. 2018;90:351-71. https://doi.org/10.1007/978-981-13-2835-0_12.

4. Clements SJ, SRC. Diet, the intestinal microbiota, and immune health in aging. Crit Rev Food Sci Nutr. 2018;58(4):651-61. https://doi.org/10.1080/104 08398.2016 .1211086

5. O'Toole PW, Jeffery IB. Gut microbiota and aging. Science. 2015;350(6265): 1214-5. https://doi.org/10.1126/science.aac8469.

6. Boehme M, van de Wouw M, Bastiaanssen TFS, Olavarria-Ramirez L, Lyons K, Fouhy F, et al. Mid-life microbiota crises: middle age is associated with pervasive neuroimmune alterations that are reversed by targeting the gut microbiome. Mol Psychiatry. 2019. https://doi.org/10.1038/s41380-019-0425-1.

7. Karvonen-Gutierrez C, Kim C. Association of Mid-Life Changes in Body Size, Body Composition and Obesity Status with the Menopausal Transition. Healthcare (Basel). 2016:4(3). https://doi.org/10.3390/healthcare4030042.

8. Karvonen-Gutierrez CA, Peng Q, Peterson M, Duchowny K, Nan B, Harlow S. Low grip strength predicts incident diabetes among mid-life women: the Michigan study of Women's health across the nation. Age Ageing. 2018; 47(5):685-91. https://doi.org/10.1093/ageing/afy067.

9. Pedditizi E, Peters $R$, Beckett $N$. The risk of overweight/obesity in mid-life and late life for the development of dementia: a systematic review and meta-analysis of longitudinal studies. Age Ageing. 2016;45(1):14-21. https:// doi.org/10.1093/ageing/afv151.

10. Knopman DS, Gottesman RF, Sharrett AR, Tapia AL, DavisThomas S, Windham BG, et al. Midlife vascular risk factors and midlife cognitive status in relation to prevalence of mild cognitive impairment and dementia in later life: the atherosclerosis risk in communities study. Alzheimers Dement. 2018;14(11):1406-15. https://doi.org/10.1016/j.jalz.2018.03.011.

11. Langille MG, Meehan CJ, Koenig JE, Dhanani AS, Rose RA, Howlett SE, et al. Microbial shifts in the aging mouse gut. Microbiome. 2014;2(1):50. https:// doi.org/10.1186/s40168-014-0050-9.

12. van der Lugt B, Rusli F, Lute C, Lamprakis A, Salazar E, Boekschoten MV, et al. Integrative analysis of gut microbiota composition, host colonic gene expression and intraluminal metabolites in aging C57BL/6J mice. Aging. 2018;10(5):930-50. https://doi.org/10.18632/aging.101439.

13. Smith P, Willemsen D, Popkes M, Metge F, Gandiwa E, Reichard M, et al Regulation of life span by the gut microbiota in the short-lived African turquoise killifish. Elife. 2017;6. https://doi.org/10.7554/eLife.27014.

14. Shen X, Miao J, Wan Q, Wang S, Li M, Pu F, et al. Possible correlation between gut microbiota and immunity among healthy middle-aged and elderly people in Southwest China. Gut Pathog. 2018;10:4. https://doi.org/1 0.1186/s13099-018-0231-3 
15. Kasubuchi M, Hasegawa S, Hiramatsu T, Ichimura A, Kimura I. Dietary gut microbial metabolites, short-chain fatty acids, and host metabolic regulation. Nutrients. 2015;7(4):2839-49. https://doi.org/10.3390/nu7042839.

16. Morrison DJ, Preston T. Formation of short chain fatty acids by the gut microbiota and their impact on human metabolism. Gut Microbes. 2016; 7(3):189-200. https://doi.org/10.1080/19490976.2015.1134082.

17. Vallianou N, Stratigou T, Christodoulatos GS, Dalamaga M. Understanding the role of the gut microbiome and microbial metabolites in obesity and obesityassociated metabolic disorders: current evidence and perspectives. Curr Obes Rep. 2019;8(3):317-32. https://doi.org/10.1007/s13679-019-00352-2.

18. Canfora EE, Meex RCR, Venema K, Blaak EE. Gut microbial metabolites in obesity, NAFLD and T2DM. Nat Rev Endocrinol. 2019;15(5):261-73. https:// doi.org/10.1038/s41574-019-0156-Z.

19. Chambers ES, Preston T, Frost G, Morrison DJ. Role of gut microbiotagenerated short-chain fatty acids in metabolic and cardiovascular health. Curr Nutr Rep. 2018;7(4):198-206. https://doi.org/10.1007/s13668-018-0248-8.

20. Dalile B, Van Oudenhove L, Vervliet B, Verbeke K. The role of short-chain fatty acids in microbiota-gut-brain communication. Nat Rev Gastroenterol Hepatol. 2019;16(8):461-78. https://doi.org/10.1038/s41575-019-0157-3.

21. Rampelli S, Candela M, Turroni S, Biagi E, Collino S, Franceschi C, et al. Functional metagenomic profiling of intestinal microbiome in extreme ageing. Aging. 2013;5(12):902-12. https://doi.org/10.18632/aging.100623.

22. Unger MM, Spiegel J, Dillmann KU, Grundmann D, Philippeit H, Burmann J, et al. Short chain fatty acids and gut microbiota differ between patients with Parkinson's disease and age-matched controls. Parkinsonism Relat Disord. 2016;32:66-72. https://doi.org/10.1016/j.parkreldis.2016.08.019.

23. Hidalgo-Cantabrana C, Delgado S, Ruiz L, Ruas-Madiedo P, Sanchez B, Margolles A. Bifidobacteria and Their Health-Promoting Effects. Microbiol Spectr. 2017;5(3). https://doi.org/10.1128/microbiolspec.BAD-0010-2016.

24. Kleessen B, Sykura B, Zunft HJ, Blaut M. Effects of inulin and lactose on fecal microflora, microbial activity, and bowel habit in elderly constipated persons. Am J Clin Nutr. 1997;65(5):1397-402. https://doi.org/10.1093/ajen/65.5.1397.

25. Bouhnik Y, Achour L, Paineau D, Riottot M, Attar A, Bornet F. Four-week short chain fructo-oligosaccharides ingestion leads to increasing fecal bifidobacteria and cholesterol excretion in healthy elderly volunteers. Nutr J. 2007:6:42. https://doi.org/10.1186/1475-2891-6-42.

26. Williams CF, Walton GE, Jiang L, Plummer S, Garaiova I, Gibson GR. Comparative analysis of intestinal tract models. Annu Rev Food Sci Technol. 2015;6:329-50. https://doi.org/10.1146/annurev-food-022814-015429.

27. Macfarlane GT, Macfarlane S. Models for intestinal fermentation: association between food components, delivery systems, bioavailability and functional interactions in the gut. Curr Opin Biotechnol. 2007;18(2):156-62. https://doi. org/10.1016/j.copbio.2007.01.011.

28. Pompei A, Cordisco L, Raimondi S, Amaretti A, Pagnoni UM, Matteuzzi $D$, et al. In vitro comparison of the prebiotic effects of two inulin-type fructans. Anaerobe. 2008;14(5):280-6. https://doi.org/10.1016/j.anaerobe.2 008.07.002.

29. Wang X, Gibson GR. Effects of the in vitro fermentation of oligofructose and inulin by bacteria growing in the human large intestine. J Appl Bacteriol. 1993;75(4):373-80. https://doi.org/10.1111/j.1365-2672.1993.tb02 790.x.

30. Vulevic J, Drakoularakou A, Yaqoob P, Tzortzis G, Gibson GR. Modulation of the fecal microflora profile and immune function by a novel transgalactooligosaccharide mixture (B-GOS) in healthy elderly volunteers. Am J Clin Nutr. 2008;88(5):1438-46. https://doi.org/10.3945/ajcn.2008.26242.

31. Walton GE, van den Heuvel EG, Kosters MH, Rastall RA, Tuohy KM, Gibson GR. A randomised crossover study investigating the effects of galacto-oligosaccharides on the faecal microbiota in men and women over 50 years of age. Br J Nutr. 2012; 107(10):1466-75. https://doi.org/10.1017/S0007114511004697.

32. Wu Q, Pi X, Liu W, Chen H, Yin Y, Yu HD, et al. Fermentation properties of isomaltooligosaccharides are affected by human fecal enterotypes. Anaerobe. 2017;48:206-14. https://doi.org/10.1016/j.anaerobe.2017.08.016.

33. Dolberg $P$, Ayalon L. Subjective meanings and identification with middle age. Int J Aging Hum Dev. 2018;87(1):52-76. https://doi.org/10.1177/009141 5017721932.

34. Ghosh TS, Das M, Jeffery IB, O'Toole PW. Adjusting for age improves identification of gut microbiome alterations in multiple diseases. eLife. 2020; 9. https://doi.org/10.7554/eLife.50240.

35. Kato K, Odamaki T, Mitsuyama E, Sugahara H, Xiao J-z, Osawa R. Age-related changes in the composition of gut Bifidobacterium species. Curr Microbiol. 2017;74(8):987-95. https://doi.org/10.1007/s00284-017-1272-4.
36. Lopez-Siles M, Duncan SH, Garcia-Gil $\sqcup$, Martinez-Medina M. Faecalibacterium prausnitzii: from microbiology to diagnostics and prognostics. ISME J. 2017;11(4): 841-52. https:/doi.org/10.1038/ismej.2016.176.

37. Trachsel J, Humphrey S, Allen HK. Butyricicoccus porcorum sp. nov., a butyrate-producing bacterium from swine intestinal tract. Int J Syst Evol Microbiol. 2018;68(5):1737-42. https://doi.org/10.1099/ijsem.0.002738.

38. Smith NW, Shorten PR, Altermann EH, Roy NC, McNabb WC. Hydrogen cross-feeders of the human gastrointestinal tract. Gut Microbes. 2019;10(3): 270-88. https://doi.org/10.1080/19490976.2018.1546522.

39. Carbonero F, Benefiel AC, Gaskins HR. Contributions of the microbial hydrogen economy to colonic homeostasis. Nat Rev Gastroenterol Hepatol. 2012;9(9):504-18. https://doi.org/10.1038/nrgastro.2012.85.

40. Ju T, Kong JY, Stothard P, Willing BP. Defining the role of Parasutterella, a previously uncharacterized member of the core gut microbiota. ISME J. 2019;13(6):1520-34. https://doi.org/10.1038/s41396-019-0364-5.

41. Muñiz Pedrogo DA, Jensen MD, Van Dyke CT, Murray JA, Woods JA, Chen J, et al. Gut microbial carbohydrate metabolism hinders weight loss in overweight adults undergoing lifestyle intervention with a volumetric diet. Mayo Clin Proc. 2018;93(8): 1104-10. https://doi.org/10.1016/.mayocp.2018.02.019.

42. Leahy SC, Higgins DG, Fitzgerald GF, van Sinderen D. Getting better with bifidobacteria. J Appl Microbiol. 2005;98(6):1303-15. https://doi.org/10.1111/ j.1365-2672.2005.02600.x.

43. Di Gioia D, Aloisio I, Mazzola G, Biavati B. Bifidobacteria: their impact on gut microbiota composition and their applications as probiotics in infants. Appl Microbiol Biotechnol. 2014;98(2):563-77. https://doi.org/10.1007/s00253-013-5405-9.

44. Woodmansey EJ. Intestinal bacteria and ageing. J Appl Microbiol. 2007; 102(5):1178-86. https://doi.org/10.1111/j.1365-2672.2007.03400.x.

45. Ticinesi A, Nouvenne A, Cerundolo N, Catania P, Prati B, Tana C, et al. Gut Microbiota, Muscle Mass and Function in Aging: A Focus on Physical Frailty and Sarcopenia. Nutrients. 2019;11(7). https://doi.org/10.3390/nu11071633.

46. Biagi $E$, Candela M, Franceschi $C$, Brigidi P. The aging gut microbiota: new perspectives. Ageing Res Rev. 2011;10(4):428-9. https://doi.org/10.1016/j.arr.2 011.03.004.

47. Odamaki T, Kato K, Sugahara H, Hashikura N, Takahashi S, Xiao JZ, et al. Agerelated changes in gut microbiota composition from newborn to centenarian: a cross-sectional study. BMC Microbiol. 2016;16:90. https://doi. org/10.1186/s12866-016-0708-5.

48. Lan Y, Kriete A, Rosen GL. Selecting age-related functional characteristics in the human gut microbiome. Microbiome. 2013;1(1):2. https://doi.org/10.11 86/2049-2618-1-2.

49. Suzuki A, Ito M, Hamaguchi T, Mori H, Takeda $Y$, Baba R, et al. Quantification of hydrogen production by intestinal bacteria that are specifically dysregulated in Parkinson's disease. PLoS One. 2018;13(12):e0208313. https://doi.org/10.1371/journal.pone.0208313.

50. Gonzalez-Rodriguez I, Gaspar P, Sanchez B, Gueimonde M, Margolles A, Neves AR. Catabolism of glucose and lactose in Bifidobacterium animalis subsp. lactis, studied by $13 \mathrm{C}$ nuclear magnetic resonance. Appl Environ Microbiol. 2013;79(24):7628-38. https://doi.org/10.1128/AEM.02529-13.

51. Walker AW, Ince J, Duncan SH, Webster LM, Holtrop G, Ze X, et al. Dominant and diet-responsive groups of bacteria within the human colonic microbiota. ISME J. 2011;5(2):220-30. https://doi.org/10.1038/ismej.2010.118.

52. Flint HJ, Scott KP, Louis $P$, Duncan SH. The role of the gut microbiota in nutrition and health. Nat Rev Gastroenterol Hepatol. 2012;9(10):577-89. https://doi.org/10.1038/nrgastro.2012.156.

53. Sonnenburg $J$, Backhed F. Diet-microbiota interactions as moderators of human metabolism. Nature. 2016;535(7610):56-64. https://doi.org/10.1038/ nature18846.

54. Holscher HD, Bauer LL, Gourineni V, Pelkman CL, Fahey GC Jr, Swanson KS. Agave inulin supplementation affects the fecal microbiota of healthy adults participating in a randomized, double-blind, placebo-controlled, Crossover Trial. J Nutr. 2015;145(9):2025-32. https://doi.org/10.3945/jn.115.217331.

55. Marino E, Richards JL, McLeod KH, Stanley D, Yap YA, Knight J, et al. Erratum: gut microbial metabolites limit the frequency of autoimmune $T$ cells and protect against type 1 diabetes. Nat Immunol. 2017;18(11):1271. https://doi.org/10.1038/ni1117-1271c.

56. Natarajan N, Hori D, Flavahan S, Steppan J, Flavahan NA, Berkowitz DE, et al. Microbial short chain fatty acid metabolites lower blood pressure via endothelial G protein-coupled receptor 41. Physiol Genomics. 2016;48(11): 826-34. https://doi.org/10.1152/physiolgenomics.00089.2016.

57. Pluznick JL, Protzko RJ, Gevorgyan H, Peterlin Z, Sipos A, Han J, et al. Olfactory receptor responding to gut microbiota-derived signals plays a role 
in renin secretion and blood pressure regulation. Proc Natl Acad Sci U S A. 2013;110(11):4410-5. https://doi.org/10.1073/pnas.1215927110.

58. Kapoor E, Collazo-Clavell ML, Faubion SS. Weight gain in women at midlife: a concise review of the pathophysiology and strategies for management. Mayo Clin Proc. 2017;92(10):1552-8. https://doi.org/10.1016/j.mayocp.2017.08.004.

59. Fernandes J, Su W, Rahat-Rozenbloom S, Wolever TM, Comelli EM. Adiposity, gut microbiota and faecal short chain fatty acids are linked in adult humans. Nutr Diabetes. 2014;4:e121. https://doi.org/10.1038/nutd.2 014.23.

60. De Vuyst L, Leroy F. Cross-feeding between bifidobacteria and butyrateproducing colon bacteria explains bifdobacterial competitiveness, butyrate production, and gas production. Int J Food Microbiol. 2011;149(1):73-80. https://doi.org/10.1016/j.ijfoodmicro.2011.03.003.

61. Devika NT, Raman K. Deciphering the metabolic capabilities of Bifidobacteria using genome-scale metabolic models. Sci Rep. 2019;9(1): 18222. https://doi.org/10.1038/s41598-019-54696-9.

62. Fukuda S, Toh H, Hase K, Oshima K, Nakanishi Y, Yoshimura K, et al. Bifidobacteria can protect from enteropathogenic infection through production of acetate. Nature. 2011;469(7331):543-7. https://doi.org/10.103 8/nature09646.

63. Duncan SH, Barcenilla A, Stewart CS, Pryde SE, Flint HJ. Acetate utilization and butyryl coenzyme a (CoA):acetate-CoA transferase in butyrateproducing bacteria from the human large intestine. Appl Environ Microbiol. 2002;68(10):5186-90. https://doi.org/10.1128/aem.68.10.5186-5190.2002.

64. Mao $\mathrm{S}$, Huo W, Zhu W. Use of pyrosequencing to characterize the microbiota in the ileum of goats fed with increasing proportion of dietary grain. Curr Microbiol. 2013;67(3):341-50. https://doi.org/10.1007/s00284-0130371-0

65. Li M, Li G, Zhu L, Yin Y, Zhao X, Xiang C, et al. Isolation and characterization of an Agaro-oligosaccharide (AO)-hydrolyzing bacterium from the gut microflora of Chinese individuals. PLoS One. 2014;9(3):e91106. https://doi. org/10.1371/journal.pone.0091106.

66. Yin Y, Lei F, Zhu L, Li S, Wu Z, Zhang R, et al. Exposure of different bacterial inocula to newborn chicken affects gut microbiota development and ileum gene expression. ISME J. 2010;4(3):367-76. https://doi.org/10.1038/ismej.2 009.128 .

\section{Publisher's Note}

Springer Nature remains neutral with regard to jurisdictional claims in published maps and institutional affiliations.

Ready to submit your research? Choose BMC and benefit from:

- fast, convenient online submission

- thorough peer review by experienced researchers in your field

- rapid publication on acceptance

- support for research data, including large and complex data types

- gold Open Access which fosters wider collaboration and increased citations

- maximum visibility for your research: over $100 \mathrm{M}$ website views per year

At $\mathrm{BMC}$, research is always in progress.

Learn more biomedcentral.com/submissions 